\title{
A Family Assessment based on the Social Relations Model
}

\section{Introduction}

For some family therapists an empirically based family assessment is a useful tool to understand family functioning. In a special issue of the Journal of Family Therapy (Carr, 2000a), empirical approaches to family assessment were presented. In his Editorial to this special issue, Carr emphasized the strengths and limitations of these approaches, but in particularly focused on a main misunderstanding about the nature of these family assessment tools, namely that the use of these instruments would be incompatible with a socialconstructionist therapeutic positioning (Carr, 2000b). To counter this prejudice, Carr introduced the notion of a third-order practice, in which narratives from multiple sources, including results from an assessment procedure, may be incorporated within a therapeutic practice:

"...it may be useful to consider the scores from assessment instruments and the implications of these scores, not as global knowledges but as specialized local knowledges arising from conversations between rigorous researchers. This knowledge may be introduced into therapeutic conversations not as 'the truth' but as insights that have been found to hold up in many similar situations and so may be useful for the clients to take into account." (Carr, 2000b, pp. 126-127).

The present paper must be situated within this context. The assessment model presented in this paper makes no claim to be exhaustive or to offer objective facts about the family. Results of this assessment procedure are only additional sources of information in the dialogic process of constructing hypotheses, in which all participants (family members and therapist) participate. In this process therapists and clients are balancing between knowing and not knowing (Rober, 2002), and sometimes an assessment procedure may add something to a more constructive dialogic understanding. If not, clients and therapist know that the assessment tool is not meaningful for the specific family. 
Family assessment methods are always based on models about family dynamics (Beavers \& Hampson, 2000; Carr, 2000; Miller et al., 2000; Olson, 2000; Skinner et al., 2000; Thomlison, 2006; Wilkinson, 2000). This paper presents the Social Relations Model (Kenny \& La Voie, 1984; SRM) as such a model about family dynamics and reports on the SRM approach to family assessment.-An SRM family assessment is described of a family with a child that is hospitalized in a child psychiatric centre. The SRM approach to family assessment is quite recent (until now only two papers have reported on this topic, Cook and Kenny (2004) and Cook (2005)). The main purpose of the present paper is to introduce the SRM as a way of thinking about family dynamics and its usefulness for family assessment. The focus will be more on the clinical aspects of the SRM family assessment process construction of SRM hypotheses and how these hypotheses may be used in a therapeutic practice- and less on the methodological (statistical) and theoretical SRM framework.

SRM was developed by Kenny and La Voie to tackle the interdependent nature of relationships. Interdependence (Kelley, 1979) means that persons in their relationships and relational systems, like the family system, influence each other's behaviour, thoughts, and emotions. Although the notion interdependence focuses on the interdependent nature of persons in their relationships, it does not ignore the person itself. Consequently, as will be explained later, SRM also takes into account the idiosyncratic contribution of the individual to the dynamics of the family. Currently, SRM is a well-known and much used model in the domain of relationship research, family psychology, social psychology, organizational psychology, and communication research. SRM has been less applied to the domain of psychotherapy, although recently it has been used in the domain of group psychotherapy (e.g., Marcus, 2006) and in the field of family therapy (e.g., Akister \& Reibstein, 2004; McFarlane \& Cook, 2007). 
The subject of the family assessment presented in this paper is the family members' sense of influence in their family relationships (Cook, 2001). A basic assumption of systemic therapy is that family members influence each other (Hedges, 2005). Interpersonal influence is the process by which family members affect and change each other's thoughts, behaviour and emotions (Huston, 2002). Influence can be intentional or unintentional (Huston, 2002). Intentional influence refers to the process by which someone deliberately generates action to change someone else's thoughts, behaviour or emotions in order to obtain particular effects. In contrast, unintentional influence is the process by which people affect one another without particular goal-directed intentions. The process of unintentional influence can be understood as a consequence of Watzlawick's first axiom of interpersonal communication: "one cannot not communicate" (Watzlawick, Jackson, \& Beavin, 1967). A corollary of this axiom, at least within close relationships, is that one cannot not influence (Griffin, 2006). When there is interdependence, processes of influence are inevitable; that is, family members influence each other continuously, both intentionally and unintentionally. Family members have to develop a sense of making a difference (Bateson, 1979) in their family relationships, for their own personal development and for the development of the family as a system (Street, 1994). A sense of making a difference means that family members feel that their being in the relationship is meaningful for the other family member. This 'being in the relationship' may reflect intentional and unintentional influence over the other family member (De Mol \& Buysse, 2008b).

Sense of intentional and unintentional influence is only one dimension of family dynamics. Because the focus of this paper is on the usefulness of an SRM family assessment and not on the relative importance of different dimensions of family functioning, the family assessment is limited to family members' sense of influence. The central question is to 
explore if useful information about the dynamics of influence in a clinical family can be obtained by doing an SRM family assessment.

Social Relations Model (SRM): a way of thinking about family dynamics

An SRM perspective on family dynamics takes into account the multiple levels of the family system - the personality of each family member, the relationships between the various family members, and the family as a whole - and their complex interplay (Cook, 2000). SRM is designed to elucidate statistically the relative importance of each level of the family system to the family members' behaviour, feelings, and cognitions in their family relationships. Moreover, SRM provides statistical tools to investigate this way of thinking on family dynamics.

From an SRM perspective, a person's sense of influence in a specific family relationship - for example, a mother's sense of influence regarding her youngest child - can be dependent on a number of factors: the mother's personality, the personality of the youngest child, the specific mother-child relationship, and family factors. Family factors reflect the way family members associate with one another, and indicate shared views and beliefs constructed by the family members (e.g., "in our family we don't bother each other with personal problems"). The family version of the SRM (Cook, 2000; Kashy \& Kenny, 1990) provides a means of testing the relative significance of these factors. Suppose Janet and John are the children from a two-parent two-child family. First, Janet's sense of influence regarding John can be dependent on how Janet perceives her abilities to influence all family members, independent of her specific relationship with John. This factor reflects a cross-relational consistency in the beliefs of Janet. In the SRM, this is called an actor effect. Second, Janet's sense of influence regarding John can be dependent on the degree to which John is experienced as influenceable by all his family members. This factor also reflects a crossrelational consistency, but in this case a consistency in how the other family members view 
John. In the SRM, this is called a partner effect. Third, Janet's sense of influence regarding John can be dependent on the unique sense of influence Janet has regarding John; that is, it does not reflect more general characteristics of either Janet or John. In the SRM, this is called a relationship effect. Relationship effects are directional: the relationship effect from Janet to John differs from the relationship effect from John to Janet. Thus, in a four-member family, there are 12 relationship effects. Fourth, Janet's sense of influence regarding John can be dependent on the culture of the family or the family effect. Family effects measure similarity among the members of the family system.

Bidirectional theories of parent-child and family relations emphasize the role of reciprocity in the development of relationships (Kochanska, 1997; Lollis \& Kuczynski, 1997). The SRM offers the opportunity to measure reciprocity (Cook, 2001) at both the individual and the dyadic levels. At the individual level, reciprocity is measured by correlating the actor and the partner effect of the same individual. For example, a significant positive reciprocity correlation for mothers means that, the greater the mother's sense of influence in her family relationships, the greater the family members' sense of influence in relation to the mother. At the dyadic level, reciprocity is measured by correlating the relationship effects of the two persons composing a dyad. For example, a significant positive reciprocity correlation for the father-child dyad means that, the greater the father's unique sense of influence in relation to the child, the greater the child's sense of influence in relation to the father. Although not part of the standard or basic model, the SRM also provides tests for intra-generational similarities among family members (Cook, 2000; Kashy \& Kenny, 1990). Intra-generational similarity can be measured by correlating the actor effects of family members of the same generation (e.g., the correlation of the actor effects of the mothers with the actor effects of the fathers) or by correlating the partner effects of family members of the same generation (e.g., the correlation of the partner effects of the older children with the partner effects of the younger 
children). A significant positive correlation of the parents' actor effects would indicate that a greater sense of influence for the mothers goes together with a greater sense of influence for the fathers. On the other hand, a significant positive correlation of the children's partner effects would indicate that, the more the older sibling affords other family members a sense of influence, the more the younger sibling does too.

In sum, the following measures can be obtained using SRM analysis: actor effects, partner effects, relationship effects, family effect, reciprocity at the individual level, reciprocity at the dyadic (specific relationship) level, and intra-generational similarity. It is important to notice that all SRM effects should be interpreted within the context of the family dynamics. For example, mother's actor effect reflects mother's cross-relational consistency of her sense of influence within the context of the family. Mother's familial actor effect may be (and probably will be) different from mother's cross-relational consistent sense of influence at her workplace.

\section{Social Relations Model and family assessment}

The purpose of SRM family assessment is to isolate and measure the different SRM effects that affect family members' interpersonal relationships (Cook, 2005). For a two-parent two-child family, there are 4 actor effects, 4 partner effects, 12 relationship effects and 1 family effect. The SRM effects of a single family are calculated using the appropriate SRM formulas (Cook \& Kenny, 2004). In order to be useful clinically, the SRM effects of the single family must be compared to the same SRM factors from a normative sample to obtain $\mathrm{Z}$ scores. A Z score is a statistical measure and tells how a single score compares to normative data, more specifically to the sample mean of these normative data. A Z score, plus or minus 2, indicates that the particular SRM effect of the single family is extreme (i.e., 2 standard deviations above or below the sample mean) (Cook, 2005). For example, if the mother's actor effect has a $\mathrm{Z}$ score of plus 2 or more, this means that the mother experiences a large sense of 
influence in her family relationships. Or, if the father-older sibling relationship effect has a Z score of minus 2 or lower, this means that the father experiences little sense of influence in his relationship to the older sibling. Z scores should be interpreted only for SRM factors with significant variance in the normative sample (Cook \& Kenny, 2004). Reciprocity correlations cannot be calculated for a single family. However, if the actor and partner effects of a certain member of the single family are significant ( $\mathrm{Z}$ scores plus or minus 2$)$, reciprocity at the individual level can be hypothesized only when the corresponding reciprocity correlation in the normative sample is significant (Cook \& Kenny, 2004). The same goes for reciprocity at the dyadic level.

\section{Measures}

In the context of a larger study about processes of interpersonal influence in family systems (more specifically as part of the doctoral research project of the first author), several three-item scales were developed (and configured as a questionnaire) for sense of intentional and unintentional influence in family relationships and administered from a normative sample (De Mol, 2008a). Reliabilities (Cronbach's $\alpha$ ) for the three-item scales across the 12 relationships ranged from .61 to .81 . The constructs intentional and unintentional influence were generated from our qualitative research project about the phenomenology and understandings of children's influence on their parents (De Mol \& Buysse, 2008b, 2008c). Face and content validity were tested in a pilot study, where adolescents (age range $=11$ to 18 years) were asked to make comments on the comprehensibility of the items. The normative sample consisted of 50 two-parent two-child families. The ages of the participating adolescents were equivalent to the ages of the adolescents of the clinical family (one adolescent between 11 and 15 years of age and an older adolescent between 15 and 19 years of age). Because SRM demands the use of equivalent measures for each relationship, scales were developed that could be applied to each relationship. In addition to the intentionality 
factor, the valence of the outcome or effects of one's influence was manipulated in the scales. Basically, an effect can have a positive or negative valence. On the one hand, a family member can have a sense of having positive effects regarding another family member, reflecting the family member's belief about his/her ability to do things that the other family member likes. On the other hand, a family member can have a sense of having negative effects on another family member, reflecting the family member's belief about his/her ability to do things that the other family member doesn't like. In addition, both sense of influence and sense of being influenced were measured.

In sum, eight scales were developed for each construct of the 2 (intentionality: intentional vs. unintentional) x 2 (valence: positive vs. negative) x 2 (influence vs. being influenced) manipulation: sense of intentional influence with positive effect; sense of intentional influence with negative effect; sense of unintentional influence with positive effect; sense of unintentional influence with negative effect; sense of being intentionally influenced with positive effect; sense of being intentionally influenced with negative effect; sense of being unintentionally influenced with positive effect; and sense of being unintentionally influenced with negative effect.

Each scale consisted of three items. For example, an item for sense of intentional influence with positive effects was: When it is my intention to do things that ... finds pleasant, I succeed in doing them. Family members were instructed to mentally insert the name of the target family member where there was a dotted line. Items were assembled in a 7-point Likert scale format, ranging from 1 (never true) to 7 (always true). The intentionality and valence of these variables were manipulated by systematically altering item content to reflect intentional vs. unintentional outcomes and positive vs. negative outcomes. This means that for sense of intentional influence with negative effect the item was altered into: When it is my intention to do things that ... finds unpleasant, I succeed in doing them; and for sense of unintentional 
influence with positive effect: It happens that I do things that ... finds pleasant, without that having been my intention; and for sense of unintentional influence with negative effect: It happens that I do things that ... finds unpleasant, without that having been my intention. Basically the same items were used for the four scales regarding sense of being influenced. However, the personal pronouns were systematically changed to reflect that another family member is now the actor and self is now the target of the influence. For example, the item for sense of intentional influence with positive effect was changed into: When it is mother's intention to do things that I find pleasant, she succeeds in doing them.

For the present study, the four members of the clinical family were instructed to complete each of the eight scales for each of his/her three family relationships. Z scores for each SRM effect were then calculated.

\section{Clinical illustration}

\section{Introduction of the clinical family}

This family consists of: a 40-year-old mother, a 55-year-old stepfather, a daughter who is 16 , and a daughter (15 years old) who has been hospitalized for the past year in a child psychiatric centre. The family lives in Flanders, the Dutch-speaking region of Belgium. The specific type of child psychiatric centre where the girl stays is called in Flanders an "Observation and treatment centre for children and adolescents with emotional, relational, conduct, and/or developmental disorders" (the centre where the first author worked for many years as a child psychologist and family therapist). Such a centre is an open unit with the objective to reintegrate the child in her/his family system. The treatment process is intensive and consists of several approaches, including multidisciplinary assessment, individual and group psychotherapy, family therapy, remedial education, and paramedical treatment. The treatment plan is supervised by a child psychiatrist. 
Both children were born from the mother's marriage with the natural father of the children. When the youngest daughter was one year old, father abandoned his wife and children, and broke each contact with them. The children have never been in contact with their father and his whereabouts was not known. The mother and the stepfather have been living together for the past five years. The stepfather has been divorced for 10 years and has adult children from his marriage. The mother is a housekeeper; the stepfather is a retired policeman. Both daughters attend a school for technical and vocational training. Before she was hospitalized, the younger daughter was in psychotherapeutic treatment for almost two years.

The younger daughter was hospitalized because of severe aggressive behaviour (beating, kicking, fighting, cursing, and using obscene language) towards all other family members (excepting physical violence towards the stepfather) and outside the home. The child psychiatric diagnosis is Oppositional Defiant Disorder (ODD). The younger daughter says that she would like the other family members to love her, but that she is always the target of negative criticism, and that is the reason she gets so angry all the time. The mother describes the relationship between her daughters as highly discordant. The mother says she tries to intervene in the conflicts between her daughters, and that she always invests affectively in her family relations, but gets nothing in return. The mother does not feel sufficiently supported by the stepfather for her commitment to the family. The mother's life history includes sexual abuse, repudiation by her parents, and hospitalization. When she was 16 years old, she told her mother about the incest her grandfather (father of her mother) committed towards her (when she was between six and 11 years old). Her mother and father did not believe her, but instead blamed her for daring to make such "false" accusations. Mother ran away from home, became drug-dependent and was hospitalized. The stepfather says he tries to mediate in the conflicts by staying neutral. The older daughter is very angry at 
the younger daughter because her younger sister spoils the atmosphere in the family. In the older sibling's opinion, her younger sister is mentally disturbed, and the reason she (the older sibling) is not motivated to participate in family therapy is because her younger sister is the problem.

According to the family therapist, the mother's dedication to her family is immense. She tries to be an excellent mother by controlling her children excessively (e.g., mother constantly phones up her children on their GSM's, ransack their rooms when they are at school) and involving herself in each conflict between the children. As a consequence, the mother's relationship with her adolescent daughters is constantly discordant and characterized by a process of attraction and rejection. The stepfather tries to be the saviour of the family and is indeed the "glue" between the family members for the moment. However, this solution is also a problem in the system, because the stepfather is always solving the problems between the other family members. The central issue for both daughters is: how to remain connected to the family while simultaneously developing one's own identity.

\section{Results of the SRM family assessment}

In this section we present the results of the assessment. At first glance, the figures in the tables may look cold and detached from any sensitivity with the family members. Behind each figure there is a person with her/his pain, grief, hope, wishes, and so on. This means that these figures cannot have a positivistic real statute, but are merely metaphorical signposts that the family members offer in our collaborative effort to understand something of the family complexities. Results for the family members' sense of influence and sense of being influenced are reported in Table 1 and Table 2, respectively. Basic hypotheses and indications for therapeutic interventions will also be presented in this section. In-depth analysis of the SRM effects of this clinical family is provided in the discussion section. 
Sense of influence. The SRM results for sense of influence (Table 1) indicated that the clinical family's family effect for sense of intentional positive influence is significantly lower than the family factor for the sample $(Z=-2.28)$. This means that, in this family, a sense that one can intentionally please another family member is significantly less present than in the average family. On the other hand, the stepfather holds strong beliefs about his ability to have an intentional positive influence on the other family members (stepfather actor effect $\mathrm{Z}=$ 2.90). The older daughter seems to have lost a sense that she can have an intentional positive influence in this family (older daughter actor effect $Z=-3.21$ ). Only in her relationship to her stepfather does the older daughter feel that she can intentionally have a positive influence (relationship effect older daughter-stepfather $\mathrm{Z}=3.66$ ).

In her relationship to her mother, the older daughter feels low intentional positive influence (relationship effect older daughter-mother $Z=-2.03$ ). The combination of this lower sense of intentional positive influence with a higher sense of unintentional negative influence in the older daughter-mother relationship $(Z=2.30)$ deserves some attention. Apparently, the older daughter experiences alienation in her relationship to her mother: while, from her perspective, she fails to intentionally please her mother, she is aware of unintentional influence on her mother but only with respect to negative effects. Presumably, in the relationship with her mother, she experiences something of the nature that "whatever I do, it will not please my mother". Perhaps this is one reason that she idealizes the relationship with her stepfather, and this idealization consolidates his position as saviour of the family.

In addition, the older daughter has a high sense that she can intentionally displease her sister (older daughter-younger daughter relationship effect $Z=3.00$ ). Besides being angry at her younger sister, this high sense of intentional negative influence might indicate aggression from the older daughter towards the younger daughter. On the other hand, the younger daughter experiences her influence on her older sister quite differently. SRM disentangles 
relationship effects and indicates that the way the older sibling experiences her influence in the relationship with her younger sister is quite different from the way the younger sibling experiences her influence in the relationship with her older sister. The polarized sense of the older daughter's positive influence in her family relationships can be further explored in the family therapy sessions.

The mother feels low intentional positive influence in the spouse relationship (motherstepfather relationship effect $Z=-2.00$ ). Although not extreme, the mother also has a higher sense of intentional negative influence towards the stepfather $(Z=1.75)$. The mother seems to be dissatisfied with her spouse relationship. The stepfather experiences his influence in the relationship with his wife quite differently. Although reciprocity in the mother-father relationship was found in the larger sample, reciprocity in this spouse relationship cannot be hypothesized. On the other hand, in her relationship with the younger daughter, the mother experiences a low sense of intentional negative influence (mother-younger daughter relationship effect $Z=-2.58$ ). Although the mother's relationships with her daughters are discordant, she does not feel intentional negative influence towards the younger daughter. Unfortunately, the mother-older daughter relationship effects cannot be interpreted (no significant variance in the normative sample).

The last significant score regards the higher sense of intentional negative influence of the younger daughter in her relationship with the stepfather (younger daughter-stepfather relationship effect $Z=2.11$ ). It is noteworthy that the relationship with her stepfather is the only relationship in which the younger daughter feels this intentional negative influence. The stepfather does not assess low sense of positive or high sense of negative influence in his family relationships. On the contrary, overall he has a higher sense of intentional positive influence (stepfather actor effect $Z=2.90$ ). The younger daughter's higher sense of intentional negative influence towards the stepfather probably indicates that she is questioning 
his position in the family. Family loyalties are possibly of importance, and this is a way in which the younger daughter stands up for her biological family relationships. This is another hypothesis to be explored in the family therapy.

To conclude the results of sense of influence, it is interesting to note that the scores for sense of intentional (as opposed to unintentional) influence were extreme. In addition, with the exception of two actor effects, relationship effects' scores were also extreme. Further clinical implications will be discussed later.

Sense of being influenced. The SRM results (Table 2) indicated that none of the actor effects has an extreme score. For the partner effects, the score of intentional positive influence from the younger daughter is low (younger daughter partner effect $\mathrm{Z}=-2.50$ ). This means that the family members experience low intentional positive influence from the younger daughter. However, the mother does feel positively influenced by her younger daughter, both intentionally and unintentionally (mother-younger daughter relationship effects $Z=3.93$ and $Z=3.28)$

Examining the results of sense of being influenced, several extreme scores for the relationship effects are observed. Moreover, these scores seem to form a pattern. Extreme scores for intentional positive and unintentional positive influence are similar, and each time the scores for intentional negative influence are the opposite. Moreover, the family members experience their sense of being influenced much more extremely than their sense of influence. Apparently, assessing the influence one is experiencing from others is easier and more accessible for a person than evaluating one's own influence, especially when relationships are problematic.

The older daughter assesses her sense of being influenced in her family relations extremely. She experiences low positive influence from her mother (older daughter-mother relationship effect $\mathrm{Z}$ scores $=-3.00$ and -2.62 ) and from her younger sister (older daughter- 
younger daughter relationship effect $Z$ scores $=-2.21$ and -2.51 ). Furthermore, the older daughter feels much intentional negative influence from the mother $(Z=2.02)$ and her younger sister $(Z=2.38)$. On the other hand, the older daughter's sense of being positively influenced by the stepfather is very high ( $\mathrm{Z}$ scores $=4.55$ and 4.64$)$, and her sense of being negatively influenced in her relationship with the stepfather is very low $(Z=-4.24)$. The way the older daughter is experiencing her relationships with her mother and sister is characterized by a massive feeling of being negatively influenced. And the way she experiences the influence from her stepfather indicates idealization. In combination with the older daughter's very low sense of intentional positive influence in her family relationships, family therapeutic interventions should focus on the way she experiences her family relations. Otherwise, her separation process as an adolescent could be disrupted, with possible problems in building future relationships.

The mother-younger daughter relationship and younger daughter-mother relationship show similar patterns - i.e., high sense of being positively influenced and low sense of being intentionally negatively influenced. Reciprocity between the mother and the younger daughter for their sense of being intentionally positively influenced can be hypothesized, because the corresponding reciprocity correlation in the larger sample was significant. This is a remarkable observation, because it does not conform to the mother's and the family therapist's description. Maybe this observation reveals a hidden coalition between the mother and the younger daughter. Or maybe the mother and the younger daughter have never been aware of this sense of being influenced positively by each other, because it was never brought to light. These hypotheses are other possible guides for clinical interventions.

The mother experiences low positive influence from the stepfather (mother-stepfather relationships effects $\mathrm{Z}$ scores $=-2.83$ and -2.73 ). The mother does not feel she can please the stepfather (see results for sense of influence), nor does she experience positive influence from 
him. Because the stepfather does not seem to assess his spouse relationship similarly, it would be interesting to explore his awareness of the mother's sense of their relationship in the therapeutic sessions.

The younger daughter feels low positive influence from her stepfather towards her (younger daughter-stepfather relationship effects $\mathrm{Z}$ scores $=-2.57$ and -2.26 ), and high intentional negative influence $(Z=3.15)$. On the other hand, the stepfather does not feel intentionally negatively influenced by the younger daughter (stepfather-younger daughter relationship effect $Z=-2.15)$. The way the stepfather assesses his influence and his being influenced in his family relations indeed indicates that he is trying to stay neutral. But SRM provides the opportunity to measure relationship effects. The relationship effects in which the stepfather is involved demonstrate that the way the other family members experience their influence in the relationship with the stepfather is not neutral at all. It seems that the stepfather is, reluctantly, caught up in the family tangle.

To summarize the results for both sense of influence and sense of being influenced, in particular relationship effects for intentional influence had extreme scores. Clinical implications will be discussed in the next section.

\section{Implications for therapy}

What are possible perspectives a family therapist could learn from the SRM assessment of the clinical family presented in this paper? The score for the intentional positive family effect was extreme. An extreme family effect informs the therapist about specific ways in which the family members associate with one another. In this family, the members have a low sense that they can please each other. The sense that one can please someone else does not "live" in this family (in comparison to what can be expected within the "average" family). The family therapist could hypothesize that this family has no culture in which to communicate pleasant relational experiences towards each other. Therefore, a possible guide 
for the therapy could be: because family therapy always focuses on what is going well (positive reframes), the therapist must be very deliberate when he/she explores what is still going well between the family members, as they as they do not have the habit (or skills) to think in such a way about their relations.

Only two actor effects had extreme scores (both the stepfather and the older daughter experience a sense of intentional positive influence). An actor effect informs the therapist about the person or "being" of a family member in the family, independent of a particular family relationship. The stepfather feels he can positively influence the others in the family. But the older daughter has a low sense that she can influence the other family members positively. This informs the family therapist that the older daughter does not feel well in her family relations (the older daughter has lost a sense that she can influence her family relationships positively). Her person and position in the family need special attention from the family therapist. In addition, it is remarkable that only two actor effects (out of the 32 significant actor factors in the normative sample) had extreme scores in this family. This means that the 30 other actor effects are situated in the "normal" variance. Consequently, it can be argued that the problems in this family are not associated with "personality" problems of the family members, but are due to problematic relational functioning. In other words, the person of these family members cannot be addressed as the cause of the problems (e.g., personal failure), but the problems reflect a relational or bidirectional responsibility.

Because SRM disentangles "personal" factors (actor and partner effects) and relationship factors, possible directions for clinical interventions are indicated. Relationship effects "contextualize" the person in his family relations (Cook \& Kenny, 2004) and thus offer guidelines regarding which relationships the family therapist can focus on. Consequently, interventions on the relationship level will also affect the actor and partner effects of a particular family member. For example, therapeutic interventions for the older 
daughter could focus on her relationship with the mother. If the older daughter-mother relationship could change in such a way that the older daughter would experience some sense of positive influence towards her mother, the older daughter's overall low sense of positive influence will be affected. Moreover - and this illuminates interdependence - such interventions indirectly affect the older daughter-stepfather relationship and, therefore, they could be one way of relieving the stepfather of his saviour role.

The preceding points can be reiterated for the partner effects. Only one partner effect had an extreme score (the younger daughter for sense of being intentionally positively influenced). The way the older daughter experiences the relationship with her younger sister can be of particular interest to the family therapist. The younger daughter probably has an inadequate idea about what she elicits from her older sister and, most likely, she has no idea why she has such effects on her older sister. Interventions on the level of the sibling relationship could facilitate a process with the younger sibling in which she obtains some insight into what she elicits in this relationship and, as a consequence of interdependence, in her other family relationships. That is, the younger sibling could get some sense of her partner effect.

Many relationship effects had extreme scores. This demonstrates how a family therapist can benefit from SRM. Instead of general statements about family members' feelings in the family, relationship effects provide some insight into the dynamics of the family. For example, the therapist could focus on the mother's sense of influence in her spouse relationship, especially because the stepfather experiences the relationship with his wife differently. Is there enough room for the mother to exert a positive influence towards her partner? Or is the stepfather so preoccupied with his role as saviour that the mother does not sufficiently experience herself being in the spouse relationship? 
An SRM family assessment can offer the therapist some perspectives for therapeutic interventions but states nothing about how the therapist can intervene. For example, regarding the older daughter - younger daughter relationship, therapist A can choose to tackle these issues in a directive and solution focused way, while for therapist B the SRM family assessment results can be indicative not to focus on this relationship in the first place but on the contrary to concentrate on family members' beliefs in less problem saturated relationships. Furthermore, some therapists may choose to discuss the SRM results with the family members in an open way while for other therapists these results are an indication to explore issues of interpersonal influence in this family very cautiously. SRM has no intention to curtail the creativity of the therapist, but only to give an additional tool to the therapist to tackle some complexities of family dynamics.

Still another approach is to involve the family members as full agentic partners in the complete assessment process, starting with an invitation of the therapist to the family to consider the rationale of SRM as a possible interesting model to look at the family dynamics. This rationale may be introduced not as "the truth" about family functioning, but as insights that have been found to be interesting in many other families (Carr, 2000). The idea of interdependence may help family members to differentiate and to contextualize their feelings, behaviour, and thoughts in their family relationships. For example, regarding the notion of partner effects: have family members any idea about what they elicit from the other family members? Or regarding relationship effects: it may be a relief for family members to learn that one's behaviour, thoughts, and feelings are very dependent on the specific relationship context, not only in their family, but in many families. And if the family members find SRM an interesting and useful narrative to look at their family, they may be invited to fill out the questionnaire. In a similar open way, results may be discussed with the family, always as hypotheses which are constructed on the basis of only one model about family functioning. 


\section{Conclusion}

This paper presents an illustration of the SRM approach to family assessment. The SRM model tries to grasp the complexities of a family system. SRM provides a means to disentangle the various levels of family dynamics (i.e., the individuals, the relationships, and the family), and to reveal the relative importance of these levels to family functioning. Therefore, SRM is an interesting tool for performing family assessment. However, SRM family assessment is not intended to replace the family therapist's other psychological assessment or interview-based methodologies. Instead, SRM should be viewed as a complement to other assessment techniques (Cook, 2005). Moreover, the "philosophy" of SRM offers the family therapist a model from which to approach the complexities of the family system. On the other hand, as SRM is only a punctuation regarding family dynamics, limitations are part of the model.

A limitation of the SRM family assessment tool presented in this paper is that the normative sample was rather small. A larger sample would probably have revealed other significant SRM factors, which would increase the scope of the SRM family assessment. A more fundamental issue is that the SRM family assessment is rather framed in a first order approach. Specific criticism may concern the "knowing-outsider" position of the therapist, negation of the contextual and cultural embedding of the family (influence does not stop at the borders of the family), passing over the agentic features of the family members, rather mechanical view of family relationships instead of approaching the family as a narrative context where meanings are created and co-constructed, and other possible constructivist, social constructionist, and narrative comments. Without the intention to be comprehensive, we suggest two tentative remarks. First, SRM does not provide answers regarding the meaning of an SRM effect. For example, mother's actor effect only reflects her belief about her ability to influence all other family members but does not state how this belief is 
constructed, what it means for the mother herself and what it means for the other family members. Moreover, the construction of this belief will be by definition affected by many complex sources of influence of which many are probably not directly related with family history and family life. Second, we believe that theories about family dynamics are still useful for many family therapists. But like all other family theories, SRM also provides only a punctuation regarding the reality of family complexities. SRM cannot claim essentialist knowledge but may deliver a pragmatic framework for the practitioner. 


\section{References}

Akister, J., \& Reibstein, J. (2004). Links between attachment theory and systemic practice: some proposals. Journal of Family Therapy, 26, 2-16.

Bateson, G. (1979). Mind and nature: A necessary unit. New York: Dutton.

Beavers, R., \& Hampson,R.B. (2000). The Beavers Systems Model of Family Functioning. Journal of Family Therapy, 22, 120-145.

Carr, A. (Ed.). (2000a). Empirical approaches to family assessment [Special issue]. Journal of Family Therapy, 22(2).

Carr, A. (2000b). Editorial: Empirical approaches to family assessment. Journal of Family Therapy, 22, 121-127.

Cook, W.L. (2000). Understanding attachment security in family context. Journal of Personality and Social Psychology, 78, 285-294.

Cook, W.L. (2001). Interpersonal influence in family systems: A social relations model analysis. Child Development, 72 (4), 1179-1197.

Cook, W.L. (2005). The SRM approach to family assessment: An introduction and case example. European Journal of Psychological Assessment, 21, 216-225.

Cook, W.L., \& Kenny, D.A. (2004). Application of the social relations model to family assessment. Journal of Family Psychology, 18, 361-371.

De Mol, J. (2008a). Children's influence and processes of interpersonal influence in family systems. Unpublished doctoral dissertation, Ghent University, Belgium.

De Mol, J., \& Buysse, A. (2008b). The phenomenology of children's influence on parents. Journal of Family Therapy, 30, 163-193.

De Mol, J., \& Buysse, A. (2008c). Understandings of children's influence in parent-child relationships: A Q-methodological study. Journal of Social and Personal Relationships, 25, 359-379. 
Griffin, E.A. (2006). A first look at communication theory (6th ed.). New-York: McGrawHill.

Hedges, F. (2005). An introduction to systemic therapy with individuals: A social constructionist approach. Hampshire: Palgrave Macmillan.

Huston, T.L. (2002). Power. In H.H. Kelley, E. Berschied, A. Christensen, J. Harvey, T.L. Huston, G. Levinger, E. McClintock, L.A. Peplau, \& D.R. Peterson (Eds.), Close relationships (pp. 169-219). New York: Freeman.

Kashy, D.A., \& Kenny, D.A. (1990). Analysis of family research designs: A model of interdependence. Communication Research, 17, 462-482.

Kelley, H. H. (1979). Personal relationships. Hillsdale, NJ: Erlbaum.

Kenny, D.A., \& La Voie, L. (1984). The social relations model. In L. Berkowitz (Ed.), Advances in experimental social psychology (Vol. 18, pp. 141-182). New York: Academic Press.

Kochanska, G. (1997). Mutually responsive orientation between mothers and their young children: Implication for early socialization. Child Development, 68, 94-112.

Lollis, S., \& Kuczynski, L. (1997). Beyond one hand clapping: Seeing bidirectionality in parent-child relations. Journal of Social and Personal Relationships, 14, 441-461.

Marcus, D.K. (2006). Interpersonal feedback: A social relations perspective. International Journal of Group Psychotherapy, 56, 173-189.

McFarlane, W.R., \& Cook, W.L. (2007). Family expressed emotion prior to the onset of psychosis. Family Process, 46, 185-197.

Miller, I.W., Ryan, C.E., Keitner, G.I., Bishop, D.S., \& Epstein, N.B. (2000). The McMaster Approach to Families: theory, assessment, treatment and research. Journal of Family Therapy, 22, 168-189. 
Olson, D.H. (2000). Circumplex Model of Marital and Family Systems. Journal of Family Therapy, 22, 144-167.

Rober, P. (2002). Constructive hypothesizing, dialogic understanding and he therapist's inner conversation. Some ideas about knowing and not knowing in the family therapy session. Journal of Marital and Family Therapy, 28, 467-478.

Skinner, H., Steinhauer, P., \& Sitarenios, G. (2000). Family Assessment Measure (FAM) and Process Model of Family Functioning. Journal of Family Therapy, 22, 190-210.

Street, E. (1994). A family systems-approach to child parent separation: Developmental closure. Journal of Family Therapy, 16, 347-365.

Thomlison B. (Ed.) (2006). Family assessment handbook: An introductory practice guide to family assessment. Belmont: Wadsworth Publishing.

Watzlawick, P., Jackson, D.D., \& Beavin, J.H. (1967). Pragmatics of human communication: A study of interactional patterns, pathologies, and paradoxes. New York: Norton \& Co.

Wilkinson, I. (2000). The Darlington Family Assessment System: clinical guidelines for practitioners. Journal of Family Therapy, 22, 211-224. 


\begin{abstract}
A Family Assessment based on the Social Relations Model One purpose of family assessment is to formulate hypotheses that can guide clinical interventions. Family assessment is based on models about family functioning. In this paper the Social Relations Model (Kenny \& La Voie, 1984; SRM) is presented as such a model about family dynamics. Moreover, SRM provides statistical tools to underpin empirically hypotheses about family functioning. An SRM family assessment of a family with a child in child psychiatric care exemplifies the possibilities and limitations of this SRM approach to family assessment. The subject of the family assessment is family members' sense of influence in their family relationships.
\end{abstract}

